\title{
Comparison between household budget survey and 24-hour recall data in a nationally representative sample of Polish households
}

\author{
W Sekula ${ }^{1, *}, M$ Nelson ${ }^{2}$, K Figurska $^{1}, M$ Oltarzewski ${ }^{1}$, R Weisell $^{3}$ and L Szponar ${ }^{1}$ \\ ${ }^{1}$ National Food and Nutrition Institute, 61 /63 Powsinska Street, 02-903 Warsaw, Poland: ${ }^{2}$ Department of Nutrition \\ and Dietetics, King's College London, 150 Stamford Street, London SE 1 9NH, UK: ${ }^{3}$ Food and Agricultural \\ Organization, Rome, Italy
}

Submitted 3 November 2003; Accepted 25 October 2004

\begin{abstract}
Objective: Household budget survey (HBS) data are used regularly for nutritional epidemiological purposes. The validity of HBS data, however, is not well established. The aim of this project was to compare HBS and individual nutrition survey (INS) data in a nationally representative sample of Polish households.

Design: Estimates of food consumption and nutrient intake were compared between household food acquisition data collected over 1 month and a single 24-hour recall collected from every household member in a nationally representative sample of Polish households surveyed between September and November 2000. To facilitate the comparison, INS food consumption data excluded food eaten away from home and were modified using a computer program to estimate food 'as purchased' (including disaggregation of recipe data) and to allow for wastage.

Setting: Poland.

Subjects: Participants were 3716 individuals in 1215 households (representing cooperation rates of $86.2 \%$ and $89.2 \%$, respectively).

Results: Good agreement was shown between median estimates of foods such as potatoes, vegetables (including processed), meat, meat products and poultry, and animal fats (excluding butter), but agreement was poor for bread and rolls, fruit, vegetable fats and oils, eggs and six other food groups. Estimates of energy and nutrient intake were within $\pm 10 \%$ with the exceptions of polyunsaturated fats, potassium and vitamin $\mathrm{C}$.

Conclusions: Possible reasons for differences in findings between the two surveys include survey bias (e.g. social approval bias leading to overreporting of fruit), seasonal variations (e.g. high potato purchases between September and November) and aspects of the methodology (e.g. HBS data were based on records collected over 1 month, whereas 24-hour recall data were based on recalls collected from all household respondents on only 1 day and averaged for each household type). HBSs provide useful data for epidemiological research, but findings need to be interpreted in the light of other data regarding consumption, and numerous factors that may affect consumption need to be taken into account.
\end{abstract}

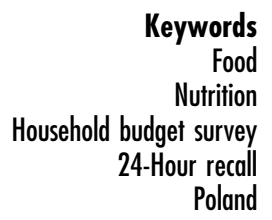

In 1989, Poland initiated a transition from a centrally planned to a market economy. This transition brought profound changes to the living conditions of its people, including access to food. Food prices increased dramatically, resulting in a considerable decline in food demand and alterations in dietary patterns ${ }^{1}$. There was growing concern about undernutrition in view of the increasing sphere of poverty. These problems were recognised by the government and were among the major problems highlighted by Poland in the report of the consultation on the follow-up to the International Conference on Nutrition in 1992 and the World Food Summit in $1996^{2}$.
Changes in the access to food and in dietary patterns were reflected in the household budget surveys (HBSs) carried out annually in Poland ${ }^{3,4}$. HBSs reveal the type of diet available to the family, expressed in terms of both food expenditure and quantities of food products over the period of a month. They also reveal differences in terms of selected socio-economic and demographic characteristics. HBSs are limited, however, in that they do not provide information on the food intakes and nutritional status of individuals, nor on the consumption of food away from home. Although a considerable number of individual dietary surveys have been conducted in the past in Poland, 
their limited scope, coverage and differences in methodology do not allow national and international comparisons.

Recent research on the validity of HBSs has compared nationally representative HBS data with individual nutrition survey (INS) data for a number of European countries $^{5-8}$. In the UK for example, a comparison ${ }^{9}$ between data from the National Food Survey ${ }^{10}$ and the National Diet and Nutrition Survey ${ }^{11}$ in adult-only households showed good agreement between acquisition and consumption of some food items (e.g. carcass meat, 'other' meat, cheese, fresh fruit and processed fruit) but poor agreement for others (e.g. fats, milk and dairy products, 'other' cereal, sugar and sugar products) even when eating away from home, wastage and recipe disaggregation had been taken into account. Such findings vary from country to country ${ }^{5}$, and it is important to be aware of such differences when making international comparisons based on HBS data, especially for epidemiological investigations.

The purpose of the present study was to compare estimates of food and nutrient availability based on HBS data collected in a nationally representative sample of Polish households with suitably adjusted estimates based on 24-hour recall data collected from all members of those households. This was expected to provide evidence of how well HBS data reflect actual consumption (suitably adjusted), given that 24-hour recall data assess consumption directly (although some misreporting by individuals may also occur). 24-Hour recall was chosen as the method that could be used with the least respondent burden to collect food consumption data from all household members and at the same time provide robust information on individual food and drink items consumed. The data also provide an opportunity to examine the ways in which socio-economic group or locality is associated with varying levels of agreement between HBS and INS data, and therefore the extent to which HBS differences between population subgroups are likely to reflect true differences in consumption.

\section{Sample and methods}

In the year 2000, a nationally representative sample of 36163 households was surveyed in the HBS conducted by the Polish Central Statistical Office. A total of 9040 households completed the survey between September and November 2000. Of these, a nationally representative cross-section of 1362 households (including 4310 individual members) was approached to provide information on individual food consumption and anthropometric data for household members aged between 0 and 96 years. The period of study, September to November, was chosen to facilitate rapid collection of data, rather than to spread the data collection over an entire year. A total of 4134 individuals (95.9\%) from 1357 households (99.6\%) provided 24-hour recall data. Not all of the 1357 households provided data for all household members, however. For the present comparison, it was important that every household member provided data. The present analysis is therefore based on data from 3716 individuals ( $86.2 \%$ of 4310 ) in 1215 households (89.2\% of 1362) who complied fully with the protocol (i.e. every member of the household provided a 24-hour recall and anthropometric data). A full description of the methods and the detailed findings are published in Polish ${ }^{12}$.

For the HBS survey, households recorded over 1 month the amount and cost of all food purchases (including the cost but not the amount of food eaten away from home), together with data on the quantities of food acquisitions from gardens, farms, allotments, gifts of food and food payments in kind. Other data collected included each household's region and locality (urban/rural), and the age, gender, socio-economic status and education level of individual household members.

Concurrent with the collection of food acquisition data in each household, all household members were asked to provide data on individual food consumption. Each household member completed one 24-hour recall in an interview conducted separately with each person. In the majority of cases, all household respondents were assessed on the same day. An album with colour photographs of 201 food items, dishes, soft drinks and alcoholic beverages commonly consumed in Poland, in three different portion sizes, was utilised to help in the assessment of portion sizes. The National Food and Nutrition Institute developed the album for the purpose of the project. Information was collected on the time and place of consumption of each item, and where necessary, its recipe. Respondents were also asked about intakes of mineral and vitamin supplements.

Height was measured using a portable stadiometer (Seca Bodymeter 208); weight was measured using digital electronic personal weighing scales (Soehnle); and arm, waist and hip circumference were measured using a flexible metal measuring tape.

Fifty regional supervisors from the Central Statistical Office HBS field force attended one of two 3-day training course at the National Food and Nutrition Institute held in June 2000. The training included instruction and practical exercises on 24-hour recall and anthropometric techniques. With the use of a training video and written materials, the regional supervisors then trained up to 40 local interviewers in their regional statistical offices. A total of 450 local interviewers were trained in this way. The training sessions were attended by appropriately experienced members of the training staff from the National Food and Nutrition Institute. Quality assurance with regard to the interviewing process and anthropometry was carried out by having regional supervisors accompany interviewers in the field and correcting any errors in protocol. With regard to the coding of data, quality assurance was carried out through scrutiny of $10 \%$ of 24 -hour recalls 
by nutritionists on the research team at the Institute in Warsaw. The error rate in coding was very low (less than $1 \%$ ) and the types of error that did occur made essentially no difference to the group estimates of average food consumption or energy and nutrient intake based on the 24-hour recall data, the basis for comparison with the HBS data.

To allow for direct comparisons between HBS and 24hour recall data, food consumption data from the 24-hour recall (normally expressed 'as eaten') were converted using a specially written computer program into the 'as purchased' equivalents (i.e. determining how much food would have had to be purchased in order to provide the amount of food on the plate, allowing for appropriate losses related to food preparation). It was not possible to convert foods 'as purchased' to foods 'as eaten' because of the many ways in which foods may be used to make composite dishes. It was possible, however, to disaggregate recipe data into constituent ingredients. Conversion of foods 'as eaten' to foods 'as purchased' thus provided a better basis for comparison. Foods from outside the household food supply (e.g. a restaurant meal purchased and eaten away from home) were not included. Quantities for food consumption and the estimated energy and nutrient content of foods from both methodologies were then compared on an 'as purchased' basis. Estimates of the availability of energy and nutrients were based on nutrient conversion factors developed by the National Food and Nutrition Institute for use with the Polish HBS data ${ }^{13}$.

Results were compared within one season (SeptemberNovember) and between the 24-hour data and the annual HBS data for 2000. The reason for making two sets of comparisons was to provide a better basis for comparison for some items (e.g. potatoes) which show marked seasonal variations in purchases that would not normally be reflected in consumption data, and at the same time to explore comparisons for items that show seasonal variations likely to affect purchases and consumption equally (e.g. vegetables other than potatoes).

\section{Results}

\section{Comparison of HBS and 24-bour recall food availability estimates}

Table 1 shows the mean (standard deviation (SD)) and median (interquartile range) estimated food acquisition, based on HBS and 24-hour recall data, for 21 food groups in a nationally representative sample of 1215 Polish households (3716 individuals aged between 0 and 96 years) surveyed between September and November 2000. For each household, the sum of the values for the 24-hour

Table 1 Mean, standard deviation (SD) and median, interquartile range (Q1 and Q3) food acquisition (g person ${ }^{-1}$ day $^{-1}$ ) in 1215 Polish households (3716 individuals aged between 0 and 96 years) based on household budget survey and 24-hour recall data collected in September-November 2000. (See text for method of calculation of 24-hour recall mean and median values)

\begin{tabular}{|c|c|c|c|c|c|c|c|c|c|c|c|c|c|}
\hline \multirow[b]{2}{*}{ Food group } & \multicolumn{5}{|c|}{ Household budget survey } & \multicolumn{5}{|c|}{ 24-Hour recall } & \multicolumn{2}{|c|}{$\begin{array}{c}\log \% \\
\text { difference* }\end{array}$} & \multirow[b]{2}{*}{$P$-value } \\
\hline & Mean & SD & Median & Q1 & Q3 & Mean & SD & Median & Q1 & Q3 & Mean & Median & \\
\hline Bread and rolls & 232.7 & 103.2 & 213.6 & 162.2 & 285.8 & 171.8 & 84.9 & 162.5 & 115.0 & 211.7 & 30.2 & 27.2 & 0.000 \\
\hline Flour & 40.8 & 57.2 & 29.2 & 8.3 & 55.6 & 18.3 & 30.8 & 7.0 & 1.0 & 18.3 & 77.3 & 132.8 & 0.000 \\
\hline $\begin{array}{l}\text { Other cereals and } \\
\text { cereals products }\end{array}$ & 41.3 & 37.5 & 31.8 & 16.4 & 54.0 & 64.6 & 76.9 & 39.1 & 6.0 & 90.0 & -43.9 & -20.1 & 0.000 \\
\hline Potatoes & 566.8 & 997.0 & 250.0 & 133.3 & 444.4 & 267.8 & 204.0 & 262.5 & 107.6 & 402.8 & 74.8 & -4.9 & 0.000 \\
\hline $\begin{array}{l}\text { Vegetables } \\
\text { (including processed) }\end{array}$ & 294.6 & 282.8 & 216.7 & 127.5 & 358.2 & 239.2 & 171.2 & 205.2 & 119.0 & 320.0 & 20.8 & 5.4 & 0.001 \\
\hline $\begin{array}{l}\text { Fruit (including processed) } \\
\text { and nuts }\end{array}$ & 217.9 & 196.4 & 170.1 & 97.0 & 279.9 & 310.8 & 231.1 & 272.5 & 150.0 & 426.7 & -35.4 & -46.9 & 0.000 \\
\hline Meat, meat products and poultry & 199.3 & 107.2 & 177.5 & 124.3 & 244.2 & 200.3 & 149.0 & 174.5 & 94.7 & 277.9 & -0.5 & 1.7 & 0.096 \\
\hline Carcass meat and poultry & 119.1 & 81.5 & 102.9 & 66.1 & 153.3 & 134.3 & 132.0 & 118.0 & 6.5 & 204.0 & -11.9 & -13.6 & 0.843 \\
\hline Meat products (excluding offal) & 80.2 & 48.6 & 69.6 & 46.9 & 101.4 & 66.0 & 62.9 & 50.0 & 20.0 & 96.0 & 19.2 & 32.5 & 0.000 \\
\hline Fish and fish products & 13.9 & 18.4 & 8.4 & 0.0 & 18.7 & 16.8 & 62.1 & 0.0 & 0.0 & 0.0 & -17.5 & 224.1 & 0.000 \\
\hline Animal fats (excluding butter) & 9.0 & 19.4 & 0.0 & 0.0 & 11.1 & 7.0 & 13.8 & 0.0 & 0.0 & 9.1 & 22.4 & 0.0 & 0.001 \\
\hline Vegetable fats and oils & 39.0 & 27.8 & 33.3 & 20.1 & 50.8 & 27.9 & 26.2 & 21.3 & 8.4 & 40.7 & 32.6 & 43.1 & 0.000 \\
\hline Butter & 12.4 & 15.1 & 7.3 & 0.0 & 18.8 & 16.0 & 19.5 & 10.0 & 0.0 & 25.8 & -23.6 & -28.2 & 0.095 \\
\hline Liquid milk & 202.7 & 161.2 & 171.5 & 85.8 & 281.6 & 130.9 & 144.4 & 90.7 & 0.0 & 218.0 & 43.5 & 63.2 & 0.000 \\
\hline Cheese & 30.5 & 24.2 & 25.0 & 14.2 & 39.6 & 36.6 & 46.7 & 20.0 & 0.0 & 55.0 & -18.0 & 21.4 & 0.000 \\
\hline $\begin{array}{l}\text { Other dairy products and } \\
\text { milk beverages }\end{array}$ & 34.7 & 34.3 & 25.0 & 12.5 & 46.8 & 34.2 & 58.8 & 13.7 & 0.0 & 37.5 & 1.4 & 57.0 & 0.000 \\
\hline Eggs & 25.6 & 17.3 & 23.4 & 14.1 & 33.3 & 26.7 & 37.5 & 7.5 & 0.0 & 43.7 & -4.2 & 105.5 & 0.000 \\
\hline Sugar & 60.8 & 68.0 & 44.4 & 20.0 & 83.3 & 39.2 & 26.4 & 34.7 & 20.0 & 53.4 & 43.0 & 24.0 & 0.000 \\
\hline $\begin{array}{l}\text { Sugar products } \\
\text { and confectionery }\end{array}$ & 9.8 & 12.4 & 6.3 & 1.3 & 13.5 & 9.4 & 27.8 & 0.0 & 0.0 & 12.4 & 3.8 & 198.8 & 0.000 \\
\hline Alcoholic beverages & 24.5 & 68.5 & 0.0 & 0.0 & 22.2 & 36.8 & 108.5 & 0.0 & 0.0 & 0.0 & -39.7 & 0.0 & 0.000 \\
\hline Kitchen salt & 11.7 & 20.2 & 5.2 & 0.0 & 16.7 & 5.2 & 2.8 & 5.0 & 3.5 & 6.7 & 71.3 & 3.3 & 0.145 \\
\hline
\end{tabular}

${ }^{*} \log \%$ difference $=[\ln ($ HBS $)-\ln (24-$ hour $)] \times 100$

†Difference between medians, Mann-Whitney test. 
recalls for all household members was divided by the number of household members to yield a single value for the household. The mean and median values for the 24-hour recall data are therefore based on 1215 observations, as for the HBS data. For all food groups, the coefficient of variation $(\mathrm{SD} /$ mean $\times 100)$ is above $50 \%$ for both HBS and INS values. This reflects the nonparametric character of the data, with many zero values and some very large values (especially for the HBS data, e.g. potatoes).

Although, strictly speaking, HBS and 24-hour recall data are paired, the average of one day's food and drink availability based on the 24-hour recall food consumption data of all household members would not, when suitably adjusted, be expected to be equal to the average availability based on the household's HBS data collected over one month. For this reason, and because the data for each group are non-parametric, the comparison between the two sets of observations was based on the MannWhitney test rather than the Wilcoxon signed rank test. For all food groups except meat, meat products and poultry, the meat subgroup carcass meat and poultry, and butter, the medians were statistically significantly different between the two methods.

To account for the possibility that seasonal differences in food purchasing might not be reflected in food consumption data (e.g. main crop potatoes are purchased in bulk during September-November but consumption varies proportionately much less between seasons), Table 2 shows the comparison between HBS data averaged over the entire year $(n=36163)$ and the 24-hour recall data in 1215 households. Again, with the exception of potatoes, meat, meat products and poultry, and carcass meat and poultry, the medians were statistically significantly different between the two methods.

Figure 1 summarises the differences between the two sets of comparisons. For each food group, the first bar represents the $\log \%$ difference* between the mean HBS and 24-hour recall data collected between September and November 2000 in 1215 households (Table 1). The second bar represents the $\log \%$ difference between medians. The next two bars represent the log \% difference (for means and medians, respectively) between the annual HBS data ( $n=36163)$ and the 24-hour recall data $(n=1215)$ collected between September and November 2000

${ }^{*} \log \%$ difference $=[\ln ($ HBS $)-\ln (24$-hour $)] \times 100$. It is a value that avoids the necessity to assume that one or the other of the observed values should be in the denominator. Because some median values were equal to zero, the equation was modified by adding 1 to every value to avoid values of 0 for arguments in the logarithmic function. The equation used in practice was therefore: $\log \%$ difference $=[\ln ($ HBS +1$)-\ln (24$-hour +1$)] \times 100$. Because there were few values of reported 'as purchased' availability less than 1 and $\ln (1)=0$, the choice of ' 1 ' for the constant yields results that are likely to reflect meaningfully the differences between methods. Any other value would be more likely to introduce a bias in the computation.
(Table 2). Where the $\log \%$ difference is positive, the reported food acquisition (HBS) was greater than the 'as purchased' estimate of food and drink availability based on reported consumption (24-hour recall) adjusted for foods eaten away from home and the disaggregation of recipe data; where the $\log \%$ difference is negative, reported 'as purchased' availability (suitably adjusted) was greater than reported food acquisition. The food groups for which the differences between HBS and 24-hour recall data did not reach significance $(P>0.05)$ are indicated by either an asterisk (*) for comparisons between the September-November data or a hash (\#) for the annual HBS versus the September-November 24-hour recall data.

Given the very considerable variation in the relationships between HBS and INS data for the two sets of comparisons and between means and medians, it is worth reflecting on possible explanations for the observed differences for each food group separately.

\section{Bread and rolls}

Acquisition of bread and rolls was 24-30\% greater than adjusted 24-hour consumption for all four measures of comparison. This is consistent with the notion that a proportion of purchased bread and rolls is likely to be wasted.

\section{Flour}

The large excess of flour purchased over flour 'availability' based on 24-hour recall data may reflect higher rates of incorporation of flour into recipes than was revealed in the recipe disaggregation process. Also, householders may have simplified cooking practices and done less baking during the survey period.

\section{Other cereals and cereals products}

Greater apparent availability based on INS compared with HBS data is likely to reflect the use of foods in store (e.g. grains, pasta, breakfast cereals) to be replenished later. The best agreement $(-20 \%)$ was between medians in the September-November data.

\section{Potatoes}

Mean acquisition of potatoes in September-November was substantially (75\%) greater than availability based on INS data. This is consistent with the observed practice of purchasing potatoes cheaply in bulk during the main crop season. The median, on the other hand, agreed closely $(-5 \%)$ in spite of an apparent statistically significant difference. The median INS-based estimate in SeptemberNovember was 34\% higher than the average HBS acquisition, again reflecting seasonal variations in consumption.

\section{Vegetables (including processed)}

Although differences were statistically significant, there was apparently good agreement (within 5.4\%) between vegetable HBS acquisition and INS-based estimates in the 
Table 2 Mean, standard deviation (SD) and median, interquartile range (Q1 and Q3) food acquisition (g person ${ }^{-1}$ day $^{-1}$ ) in Polish households, comparing household budget survey data collected in January-December 2000 ( $n=36163$ households) and 24-hour recall data collected in September-November 2000 (3716 respondents living in 1215 households). (See text for method of calculation of 24-hour recall mean and median values)

\begin{tabular}{|c|c|c|c|c|c|c|c|c|c|c|c|c|c|}
\hline \multirow[b]{2}{*}{ Food group } & \multicolumn{5}{|c|}{ Household budget survey } & \multicolumn{5}{|c|}{ 24-Hour recall } & \multicolumn{2}{|c|}{$\begin{array}{c}\log \% \\
\text { difference* }\end{array}$} & \multirow[b]{2}{*}{$P$-value $\dagger$} \\
\hline & Mean & SD & Median & Q1 & Q3 & Mean & SD & Median & Q1 & Q3 & Mean & Median & \\
\hline Bread and rolls & 225.3 & 106.3 & 206.4 & 154.7 & 274.2 & 171.8 & 84.9 & 162.5 & 115.0 & 211.7 & 26.9 & 23.8 & 0.000 \\
\hline Flour & 42.4 & 57.6 & 32.3 & 8.1 & 58.3 & 18.3 & 30.8 & 7.0 & 1.0 & 18.3 & 81.0 & 142.6 & 0.000 \\
\hline Other cereals and cereals products & 38.7 & 38.3 & 28.9 & 14.4 & 50.5 & 64.6 & 76.9 & 39.1 & 6.0 & 90.0 & -50.2 & -29.4 & 0.004 \\
\hline Potatoes & 279.4 & 526.5 & 186.2 & 50.0 & 322.6 & 267.8 & 204.0 & 262.5 & 107.6 & 402.8 & 4.2 & -34.2 & 0.135 \\
\hline Vegetables (including processed) & 206.0 & 199.4 & 152.9 & 89.3 & 257.8 & 239.2 & 171.2 & 205.2 & 119.0 & 320.0 & -14.9 & -29.3 & 0.000 \\
\hline Fruit (including processed) and nuts & 180.0 & 171.3 & 135.2 & 72.3 & 234.8 & 310.8 & 231.1 & 272.5 & 150.0 & 426.7 & -54.4 & -69.7 & 0.000 \\
\hline Meat, meat products and poultry & 195.9 & 118.3 & 171.9 & 118.5 & 243.9 & 200.3 & 149.0 & 174.5 & 94.7 & 277.9 & -2.2 & -1.5 & 0.428 \\
\hline Carcass meat and poultry & 115.6 & 92.0 & 96.8 & 60.1 & 146.7 & 134.3 & 132.0 & 118.0 & 6.5 & 204.0 & -14.9 & -19.6 & 0.200 \\
\hline Meat products (excluding offal) & 80.3 & 49.8 & 69.8 & 46.8 & 101.5 & 66.0 & 62.9 & 50.0 & 20.0 & 96.0 & 19.3 & 32.8 & 0.000 \\
\hline Fish and fish products & 16.6 & 23.7 & 9.2 & 1.3 & 21.7 & 16.8 & 62.1 & 0.0 & 0.0 & 0.0 & -1.4 & 232.2 & 0.000 \\
\hline Animal fats (excluding butter) & 8.3 & 17.6 & 0.0 & 0.0 & 9.7 & 7.0 & 13.8 & 0.0 & 0.0 & 9.1 & 14.4 & 0.0 & 0.004 \\
\hline Vegetable fats and oils & 36.7 & 27.8 & 30.9 & 17.5 & 48.9 & 27.9 & 26.2 & 21.3 & 8.4 & 40.7 & 26.7 & 35.8 & 0.000 \\
\hline Butter & 11.6 & 14.9 & 6.7 & 0.0 & 17.8 & 16.0 & 19.5 & 10.0 & 0.0 & 25.8 & -29.7 & -35.7 & 0.001 \\
\hline Liquid milk & 198.6 & 179.3 & 154.5 & 74.8 & 266.1 & 130.9 & 144.4 & 90.7 & 0.0 & 218.0 & 41.4 & 52.8 & 0.000 \\
\hline Cheese & 30.1 & 24.9 & 24.6 & 13.3 & 40.3 & 36.6 & 46.7 & 20.0 & 0.0 & 55.0 & -19.0 & 19.8 & 0.000 \\
\hline $\begin{array}{l}\text { Other dairy products and } \\
\text { milk beverages }\end{array}$ & 39.5 & 44.9 & 28.2 & 10.6 & 53.4 & 34.2 & 58.8 & 13.7 & 0.0 & 37.5 & 14.0 & 68.6 & 0.000 \\
\hline Eggs & 26.4 & 19.7 & 23.3 & 13.4 & 33.3 & 26.7 & 37.5 & 7.5 & 0.0 & 43.7 & -1.4 & 105.0 & 0.000 \\
\hline Sugar & 63.4 & 70.8 & 48.4 & 20.0 & 83.3 & 39.2 & 26.4 & 34.7 & 20.0 & 53.4 & 47.2 & 32.5 & 0.000 \\
\hline Sugar products and confectionery & 10.6 & 14.6 & 6.5 & 1.6 & 14.4 & 9.4 & 27.8 & 0.0 & 0.0 & 12.4 & 10.9 & 201.5 & 0.000 \\
\hline Alcoholic beverages & 27.9 & 88.8 & 2.8 & 0.0 & 28.2 & 36.8 & 108.5 & 0.0 & 0.0 & 0.0 & -26.8 & 133.5 & 0.000 \\
\hline Kitchen salt & 10.5 & 19.0 & 0.0 & 0.0 & 16.1 & 5.2 & 2.8 & 5.0 & 3.5 & 6.7 & 60.7 & -179.2 & 0.000 \\
\hline
\end{tabular}

${ }^{*} \log \%$ difference $=[\ln (\mathrm{HBS})-\ln (24-$ hour $)] \times 100$

†Difference between medians, Mann-Whitney test.

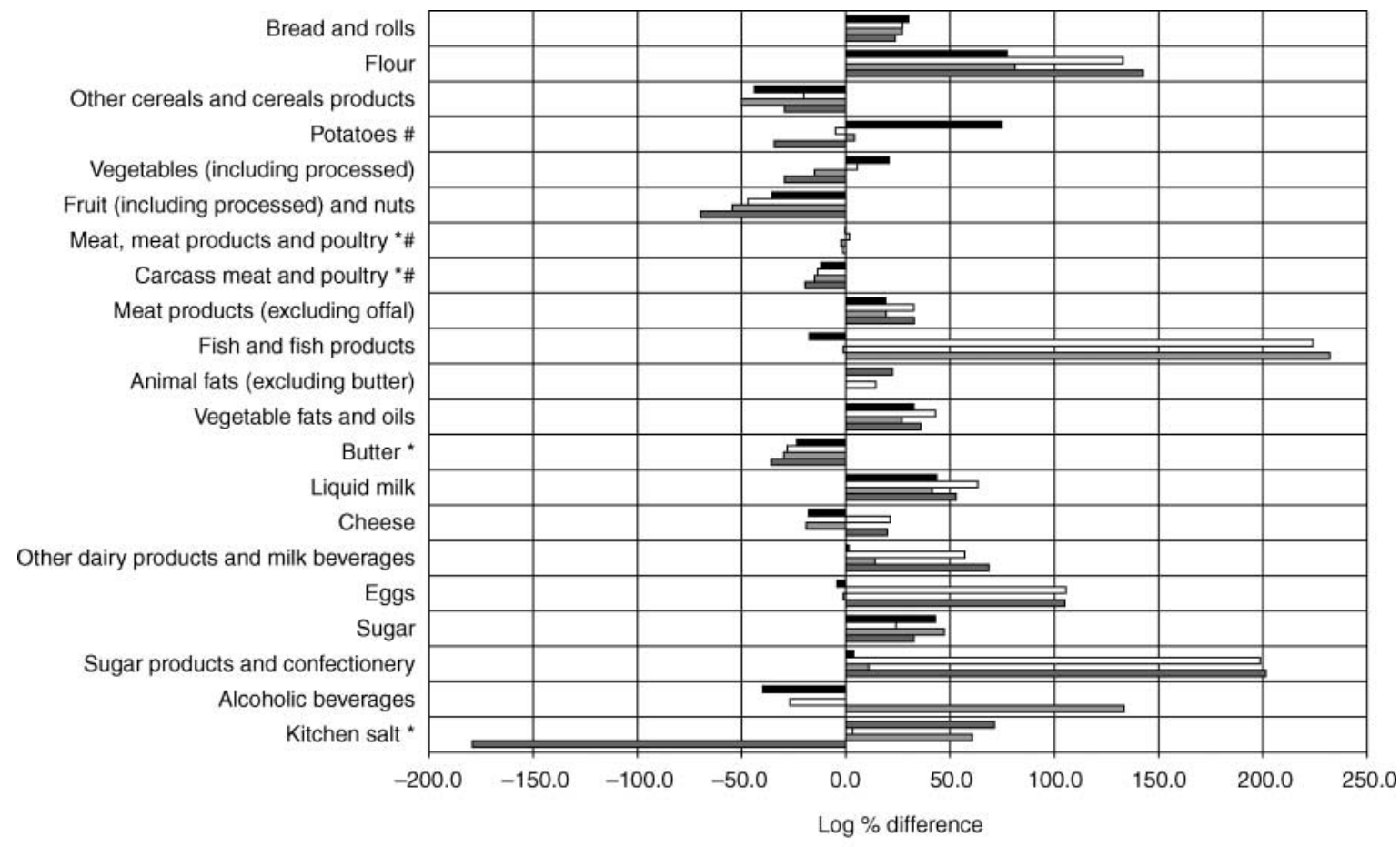

- Mean, Sep-Nov $\square$ Median, Sep-Nov $\square$ Mean, annual HBS vs. Sep-Nov 24-hour recall $\square$ Median, annual HBS vs. Sep-Nov 24-hour recall

Fig. 1 Log \% difference in median food acquisition (g person ${ }^{-1}$ day $^{-1}$ ) in 1215 Polish households based on household budget survey (HBS) and 24-hour recall data, September-November 2000. *, $P>0.05$ September-November HBS versus 24-hour recall; \#, $P>0.05$ annual HBS versus 24-hour recall 
September-November median values. The higher levels of acquisition may reflect aspects of wastage.

\section{Fruit (including processed) and nuts}

Fruit availability based on INS data was consistently greater than HBS acquisition data. This may represent an overestimate in the factors for converting fruit consumption to 'as purchased'. Alternatively, it could represent a 'social desirability'* bias in the 24-hour recall data (i.e. respondents recalled having more fruit than was actually eaten because of the associations of fruit consumption with good health).

\section{Meat, meat products and poultry}

There was excellent agreement $(<2.5 \%$ difference, $P>0.05$ ) between the HBS and 24-hour recall data for both sets of comparisons (Tables 1 and 2).

\section{Carcass meat and poultry}

Reported carcass meat and poultry acquisition based on INS data was greater than acquisition based on HBS data, although the median values did not differ significantly for either comparison. As was the case for fruit, this could represent either an error in the factors used to convert consumption to purchases or a 'social desirability' bias, respondents biasing their 24-hour reporting to favour higher-quality meat.

\section{Meat products (excluding offal)}

In contrast to carcass meat and poultry, reported 'as purchased' availability of meat products (e.g. bacon, sausage) based on the INS data was consistently below HBS-based acquisition. This may reflect the 'social undesirability' of meat products, balancing the possible positive bias relating to reported carcass meat and poultry consumption. It may also reflect an element of waste in meat products.

\section{Fish and fish products}

The agreement between mean HBS and 24-hour recall data is not reflected in the comparison between medians. This is because less than $50 \%$ of households reported consuming fish (indeed, in the September-November data, less than $25 \%$ of households reported consuming fish, hence a zero value for the third quartile). The very high values for $\log \%$ difference are primarily an artefact of the method of calculation.

\section{Animal fats (excluding butter)}

Median agreement of animal fats appears to be good because the median is zero for both HBS and 24-hour

*'Social desirability' and 'social undesirability' describe a response bias that reflects the respondent's wish to be seen to have more or less of a particular foodstuff than may in reality be the case. recall data. Mean HBS values are between 14\% (annual) and 22\% (September-November) higher than the 24-hour recall data. This may reflect uses of purchased fat in cooking that are not adequately taken into account in the disaggregation of the consumption data, and some wastage. There may also be an element of 'social undesirability' in relation to butter (see below).

\section{Vegetable fats and oils}

The HBS data for vegetable fats and oils are higher than the 24-hour recall data, possibly reflecting wastage and biases in computation similar to those suggested for animal fats.

\section{Butter}

Reported butter availability based on INS data was greater than purchasing for all comparisons. This again suggests a 'social desirability' component to the 24-hour reporting, and may in part off-set the possible biases in the reporting of the animal and vegetable fats.

\section{Liquid milk}

The high (41-63\%) differences in milk acquisition and 'as purchased' estimates of availability are likely to reflect wastage, milk used in cooking not adequately reflected in the disaggregation of the consumption data, and a tendency to underreport consumption (e.g. milk in tea and coffee not coded).

\section{Cheese}

The positive differences between median acquisitions and 'as purchased' availability for cheese contrast with the negative differences relating to the differences between means. This suggests that a relatively small number of households are consuming large amounts of cheese (hence the high mean values and large SD, especially for the 24-hour recall data), and that the contrast between the median values is probably a better reflection of usual consumption in the majority of households. The latter interpretation is also consistent with a degree of wastage.

\section{Other dairy products and milk beverages}

This group includes cream, yoghurt, fermented milks and other dairy products. While the mean HBS and INS values for the September-November data are similar, the HBS median values are higher than the INS-based values. This is likely to reflect wastage associated with these products, incomplete disaggregation of these products from recipes, and possibly some underreporting.

\section{Eggs}

Whereas the means are similar, the HBS median values are substantially greater than the INS-based values. This is likely to reflect the regularity of egg purchases within the course of a month in contrast to the relatively infrequent day-to-day consumption by individuals, as well as use 
in recipes not captured by disaggregation of consumption data.

\section{Sugar}

Higher levels of acquisition are likely to indicate greater usage in cooking than was reflected in the disaggregation of the 24-hour recall data, and possible underreporting (as for milk) in tea and coffee.

\section{Sugar products and confectionery}

The very high values for log \% difference between median values are statistical artefacts (median values being zero). The surprisingly close agreement (3.8\%) in the September-November data is more likely to reflect equal levels of underreporting in both HBS and INS data than to indicate true levels of consumption.

\section{Alcobolic beverages}

It is difficult to capture population alcohol consumption data accurately. Mean reported INS-based data were well above the reported level of acquisition (40\% in Table 1, $27 \%$ in Table 2), but three-quarters of households did not report alcohol consumption on the day of the 24-hour recall.

\section{Kitchen salt}

The large difference in the mean values is likely to reflect use in cooking that is not being fully reported in the INS data. The agreement between medians for the September-November data but not for the annual HBS versus the September-November INS data may reflect seasonal variations in salt acquisition.

For every food, the median value was lower than the mean. For animal fats and alcoholic beverages (and, in the INS, fish and fish products) the median was zero, indicating that fewer than half of the households in the study reported consumption of these items (indeed, for fish and fish products and alcoholic beverages, in the INS the third quartile is also zero). For some foods (e.g. potatoes, vegetables, kitchen salt) the size of the discrepancy between HBS and INS data was substantially less between medians than between means. For other foods, however, the $\log \%$ difference either increased markedly (meat products, vegetable fats, liquid milk, cheese, other dairy products, eggs) or decreased (fruit, sugar).

\section{Comparison of HBS and 24-bour recall estimates of energy and nutrient availability}

Because of the seasonal effects of potato and vegetable purchases on the HBS data, the mean and median values for energy and nutrient availability are generally substantially higher than the estimates of availability based on the 24-hour recall data. Log \% mean differences ranged from $-6.1 \%$ (for cholesterol) to $+52.5 \%$ (for sodium), with the log $\%$ mean difference for energy equal to $18.6 \%$. The $\log \%$ median differences also tended to be large and positive. In contrast, the log $\%$ differences between the annual HBS data and the SeptemberNovember 24-hour recall data were smaller (Table 3). The $\log \%$ median differences were within $\pm 10 \%$ except for polyunsaturated fats (PUFA) $(+14.0 \%)$, potassium $(-17.1 \%)$ and vitamin $C(-35.2 \%)$. The differences in potassium and vitamin $\mathrm{C}$ reflect the higher INS-based estimates of availability of vegetables (other than potatoes) and fruit between September and November compared with the yearly HBS average (Table 2).

\section{Discussion}

The high co-operation rates in the survey suggest that the data are likely to be highly representative of all households living in Poland. The households excluded from the analysis were on average larger than those included in the analysis (mean household size 4.04 and 3.06 persons, respectively). This reflects the lower likelihood of being able to collect 24-hour recall data from every household member in larger households.

With the major exception of potatoes and the minor exceptions of bread and rolls, vegetable fats and oils, liquid milk and cheese, the level of agreement between HBS and INS data for the September-November comparison was as good as or better than that for the annual HBS versus the September-November INS comparison. The majority of food groups showed statistically significant differences between medians for the two methods, even when the log \% differences were small. These are likely to have occurred because of the large number of households participating in the survey and the consequent sensitivity of the statistical comparisons (based on means and small standard errors or medians and large values for $n$ ). It is more difficult to interpret the physiological significance of the differences in relation to nutrition-related health. This will be more important in relation to changes in apparent consumption over time, but trend data in Poland do not exist for both datasets.

The statistical analyses may have been undermined in part by the large number of zero values for some food groups. For five food groups (fish and fish products, animal fats, butter, liquid milk, and alcoholic beverages) at least $25 \%$ of households reported neither purchases nor consumption. For cheese, other dairy products, and eggs, at least $25 \%$ of households reported no consumption in the 24-hour recall data. This introduces substantial variability into the data and makes comparisons between methods difficult to interpret. It suggests that more data at the individual level (e.g. a minimum of two 24-hour recalls and perhaps as many as four) might result in a better picture of agreement. The choice of one 24-hour recall for the present study was dictated largely by the need to have a broad, nationally representative sample of respondents 
Table 3 Mean, standard deviation (SD) and median, interquartile range (Q1 and Q3) estimates of energy and nutrient intake in 3716 respondents aged 0-96 years living in 1215 Polish households, based on annual household budget survey data and 24-hour recall data collected in September-November 2000. (See text for method of calculation of 24-hour recall mean and median values)

\begin{tabular}{|c|c|c|c|c|c|c|c|c|c|c|c|c|c|}
\hline \multirow[b]{2}{*}{ Nutrient } & \multicolumn{5}{|c|}{ Household budget survey } & \multicolumn{5}{|c|}{ 24-Hour recall } & \multicolumn{2}{|c|}{$\begin{array}{c}\text { Log \% } \\
\text { difference* }\end{array}$} & \multirow[b]{2}{*}{$P$-value } \\
\hline & Mean & SD & Median & Q1 & Q3 & Mean & SD & Median & Q1 & Q3 & Mean & Median & \\
\hline Energy (kcal) & 2571 & 1189 & 2313 & 1775 & 3069 & 2343 & 776 & 2273 & 1789 & 2794 & 9.3 & 1.8 & 0.000 \\
\hline \multicolumn{14}{|l|}{ Protein } \\
\hline Total $(\mathrm{g})$ & 75.6 & 33.6 & 68.8 & 52.7 & 90.5 & 73.6 & 26.9 & 70.7 & 53.5 & 89.5 & 2.6 & -2.8 & 0.493 \\
\hline Animal (g) & 45.7 & 22.1 & 41.5 & 30.7 & 55.7 & 46.7 & 22.1 & 44.5 & 31.2 & 58.2 & -2.2 & -7.1 & 0.012 \\
\hline Vegetable (g) & 29.8 & 16.3 & 26.2 & 19.7 & 35.5 & 26.9 & 9.3 & 25.9 & 20.3 & 32.4 & 10.5 & 1.3 & 0.009 \\
\hline \multicolumn{14}{|l|}{ Fat } \\
\hline Total $(\mathrm{g})$ & 102.1 & 50.4 & 91.4 & 68.3 & 124.3 & 97.9 & 40.9 & 92.2 & 68.1 & 120.7 & 4.3 & -1.0 & 0.378 \\
\hline SFA $(g)$ & 33.9 & 17.3 & 30.3 & 22.3 & 41.3 & 34.1 & 15.1 & 31.9 & 22.9 & 43.3 & -0.6 & -5.0 & 0.013 \\
\hline MUFA (g) & 43.1 & 22.1 & 38.3 & 28.3 & 52.5 & 40.9 & 18.5 & 38.1 & 27.7 & 50.9 & 5.2 & 0.6 & 0.049 \\
\hline PUFA (g) & 16.8 & 10.0 & 14.5 & 10.0 & 20.9 & 14.3 & 7.9 & 12.6 & 8.9 & 18.2 & 15.8 & 14.0 & 0.000 \\
\hline Available carbohydrate $(\mathrm{g})$ & 331 & 176 & 291 & 217 & 397 & 286 & 95 & 279 & 217 & 342 & 14.6 & 4.4 & 0.000 \\
\hline Dietary fibre $(\mathrm{g})$ & 23.3 & 12.8 & 20.5 & 15.3 & 27.7 & 23.4 & 8.5 & 22.3 & 17.5 & 27.7 & -0.2 & -8.8 & 0.000 \\
\hline Sodium (mg) & 6235 & 7649 & 3660 & 1891 & 8247 & 4007 & 1500 & 3868 & 2953 & 4856 & 44.2 & -5.5 & 0.944 \\
\hline Potassium (mg) & 3093 & 2259 & 2606 & 1896 & 3586 & 3198 & 1174 & 3092 & 2367 & 3903 & -3.3 & -17.1 & 0.000 \\
\hline Calcium (mg) & 599 & 312 & 534 & 385 & 736 & 559 & 272 & 531 & 350 & 724 & 6.8 & 0.5 & 0.002 \\
\hline Phosphorus (mg) & 1231 & 566 & 1109 & 858 & 1463 & 1185 & 389 & 1149 & 889 & 1431 & 3.9 & -3.6 & 0.224 \\
\hline Magnesium (mg) & 295 & 170 & 255 & 191 & 349 & 269 & 89 & 263 & 206 & 320 & 9.4 & -3.1 & 0.774 \\
\hline Iron (mg) & 11.1 & 5.3 & 9.9 & 7.6 & 13.2 & 11.2 & 4.5 & 10.4 & 8.1 & 13.2 & -1.2 & -5.0 & 0.000 \\
\hline Zinc (mg) & 10.2 & 4.5 & 9.3 & 7.2 & 12.2 & 9.9 & 3.6 & 9.4 & 7.5 & 11.9 & 3.1 & -0.8 & 0.778 \\
\hline Copper (mg) & 1.2 & 0.7 & 1.0 & 0.8 & 1.4 & 1.2 & 0.4 & 1.1 & 0.9 & 1.4 & 0.2 & -8.5 & 0.000 \\
\hline Manganese (mg) & 3.6 & 1.8 & 3.3 & 2.5 & 4.3 & 3.3 & 1.2 & 3.1 & 2.4 & 3.9 & 10.4 & 4.3 & 0.000 \\
\hline Vitamin $\mathrm{A}(\mu \mathrm{g})$ & 1174 & 770 & 996 & 683 & 1444 & 1383 & 1561 & 1010 & 696 & 1468 & -16.4 & -1.4 & 0.190 \\
\hline Thiamine (mg) & 1.51 & 0.79 & 1.33 & 1.01 & 1.79 & 1.5 & 0.7 & 1.3 & 1.0 & 1.8 & 3.8 & 1.5 & 0.142 \\
\hline Riboflavin (mg) & 1.59 & 0.74 & 1.43 & 1.08 & 1.92 & 1.6 & 0.7 & 1.5 & 1.1 & 1.9 & -0.9 & -5.2 & 0.003 \\
\hline Vitamin C (mg) & 107 & 103 & 80 & 50 & 128 & 137 & 96 & 113 & 75 & 170 & -24.2 & -35.2 & 0.000 \\
\hline Vitamin E (mg) & 12.3 & 7.1 & 10.7 & 7.5 & 15.3 & 11.8 & 6.3 & 10.5 & 7.6 & 14.7 & 4.3 & 2.2 & 0.135 \\
\hline Cholesterol (mg) & 356 & 183 & 321 & 231 & 439 & 380 & 234 & 319 & 211 & 492 & -6.4 & 0.6 & 0.482 \\
\hline
\end{tabular}

SFA - saturated fatty acids; MUFA - monounsaturated fatty acids; PUFA - polyunsaturated fatty acids.

${ }^{*} \log \%$ difference $=[\ln (\mathrm{HBS})-\ln (24$-hour $)] \times 100$.

†Difference between medians, Mann-Whitney test.

within households but with limited resources to carry out the study.

In addition to the problem of individual variability in consumption, some of the apparent differences may be due to:

- 24-hour recall methodology, including aspects of interviewer training and skills, the ability to probe fully for all items consumed, assessment of portion size, food descriptions, allocation of food codes, and proper identification of meals consumed from outside the household food supply;

- the choice of factors for converting food 'as eaten' to food 'as purchased';

- between-household variation in recipe data used for disaggregation;

- underreporting of some items and overreporting of others in the 24-hour recall data, governed partly by issues concerning body size, social desirability and social approval;

- variation in the level of wastage of different food groups; and

- underreporting of alcoholic beverage consumption for both HBS and INS data.
Furthermore, problems of interpretation arise in relation to the distribution of consumption in the population. For example, fish and alcohol were reportedly consumed (on a given day) by less than one-quarter of the population. The pattern of consumption of these foods in the population will have an important bearing on risks of cardiovascular disease, but because the HBS data are collected at the household level, the full impact of their consumption on health at the individual level cannot easily be determined from HBS data.

There was remarkable consistency in the estimates of availability of energy and nutrients from purchases and their intake from foods (Table 3). The exceptions were PUFA (log \% median differences 14\% higher in HBS data) and potassium and vitamin $\mathrm{C}$ (log \% median differences $17 \%$ and $35 \%$ higher in INS data, respectively). These differences may reflect short-term social desirability biases in the INS data (more reported (or actual) consumption of butter, fruit and vegetables, and less consumption of vegetable fats), but it is not possible to know to what extent the differences may be due to changes in purchases or reported or actual consumption.

The log \% median differences between the Polish HBS and INS data were all within $\pm 5.4 \%$ for the foods listed 
Table 4 'Good' and 'poor' agreement between household budget survey and individual nutrition survey data in Poland and the UK. (See text for definitions of 'good' and 'poor')

\begin{tabular}{|c|c|c|c|}
\hline \multirow[b]{2}{*}{ Food group } & $\begin{array}{c}\text { 'Good' } \\
\text { agreement }\end{array}$ & \multicolumn{2}{|c|}{$\begin{array}{c}\text { 'Poor' } \\
\text { agreement }\end{array}$} \\
\hline & Poland UK & Poland & UK \\
\hline Bread and rolls & & - & \\
\hline Flour & & - & \\
\hline Other cereals and cereals products & & & \\
\hline Potatoes & • & & \\
\hline Vegetables (including processed) & - & & \\
\hline Fruit (including processed) and nuts & - & - & \\
\hline Meat, meat products and poultry & - & & \\
\hline Carcass meat and poultry & - & & \\
\hline Meat products (excluding offal) & - & - & \\
\hline Fish and fish products & & & \\
\hline Animal fats (excluding butter) & - & & \\
\hline Vegetable fats and oils & & & - \\
\hline Butter & & - J & \\
\hline Liquid milk & & - 1 & \\
\hline Other dairy products and milk beverages & & - $\}$ & \\
\hline Cheese & - & & \\
\hline Eggs & & - & \\
\hline Sugar & & & - \\
\hline Sugar products and confectionery & & & \\
\hline Alcoholic beverages & - & & - \\
\hline Kitchen salt & - & & - \\
\hline
\end{tabular}

-, not included in UK comparisons.

in Table 4, indicating 'good' agreement. In the UK, the foods showing good agreement between the two surveys were carcass meat, 'other' meat (all meat and meat products not included in fresh carcass meat or offal), cheese, fresh fruit and processed fruit ${ }^{7}$. In contrast, the foods showing poor agreement between the two surveys in Poland ( $\log \%$ median difference $>20 \%$ ) were bread and rolls, flour, other cereals and cereals products, fruit (including processed) and nuts, meat products (excluding offal), vegetable fats and oils, butter, liquid milk, 'other' dairy products and milk beverages, and eggs. In the UK, poor agreement was found for fats, milk and dairy products, 'other' cereal, and sugar and sugar products (the UK food groups were less disaggregated than in the Polish data, as shown in Table 4). Some of the differences between these lists may be due to differences in the basis for comparison between the two surveys: in Poland, the findings related to all members of the household and the two samples are identical; in the UK, the comparisons are between two (theoretically) nationally representative samples of adult-only households. There is some concordance in the two countries regarding the food groups that show 'poor' agreement ('other' cereals and cereal products, some fats, and milk and milk products), but no concordance in the groups that show 'good' agreement. The contrast between the findings for meat products (excluding offal), for example - 'good' in the UK and 'poor' in Poland - highlights the importance of understanding the country-specific differences in reporting between HBS and INS data and the implications that this may have for epidemiological research, cross-country comparisons and national or EU-wide policy development. There is no obvious explanation as to why agreement is good in one country and not in another.

We conclude that the HBS data provide useful markers for the levels of consumption of foods and nutrients in households in Poland. With some exceptions that can be explained by seasonal variations, wastage and possible misreporting influenced by social desirability or social approval, the estimates of food availability and food consumption are in good agreement.

\section{Contributions}

Dr Wlodek Sekula had overall responsibility for derivation of the data from the HBS and collection of the INS data and their comparison. Dr Michael Nelson advised on methodological issues and analysis. Maciek Ołtarzewski had responsibility for development of the training materials, supervision of the data collection, and coding and conversion of the INS food consumption data to estimates of foods 'as purchased'. The work was coordinated by Dr Lucjan Szponar of the National Food and Nutrition Institute in Warsaw. All authors contributed to the present text.

\section{Acknowledgements}

The authors would like to acknowledge the work of the Central Statistical Office in the collection of data, the help of Dr Eva Rychlik in the preparation of interviewer training materials, the advice of Professor Georgy Biro, Budapest, Hungary, and the help of the many families who took the time and trouble to complete the survey. The project was implemented thanks to financial and technical assistance of the Food and Agricultural Organization of the United Nations.

\section{References}

1 Henson S, Sekuła W. Market reform in the Polish food sector: impact upon food consumption and nutrition. Food Policy 1994; 19(5): 419-42.

2 Food and Agriculture Organization of the United Nations (FAO). International Conference on Nutrition. Final Report of the Consultation on ICN Follow-up in the European Region and OECD Countries, Warsaw, Poland, 2-4 September 1996. Rome: FAO, 1997.

3 Polish Central Statistical Office. Budżety gospodarstw domowych [Annual Household Budget Survey, Poland]. Warsaw: Polish Central Statistical Office, 1990-2000.

4 Polish Central Statistical Office. Warunki życia ludności [Analysis of the Living Conditions of the Polish Population based on the Annual Polish Housebold Budget Survey]. Warsaw: Polish Central Statistical Office, 1990-2000.

5 DAFNE website: http://www.nut.uoa.gr/english/dafne/ DafneEN.htm

6 Friel S, Nelson M, McCormack K, Kelleher C, Thriskos P. Methodological issues using household budget survey expenditure data for individual food availability estimation: 
Irish experience in the DAFNE pan-European project. Public Health Nutrition 2001; 4(5B): 1143-8.

7 Paterkis S. An evaluation of the use of the National Food Survey for epidemiological purposes. PhD thesis, University of London, London, 2000.

8 Sekula W, Szponar L, Nelson M, Weisell R. A relation between household and individual food and nutrient consumption data - the Polish experience. Paper presented at the Fifth International Conference on Dietary Assessment Methods, Chiang Rai, Thailand, 26-29 January 2003; C1.5.

9 Paterakis S, Nelson M. A comparison between the National Food Survey and the Family Expenditure Survey food expenditure data. Public Health Nutrition 2003; 6(6): $571-80$
10 Ministry of Agriculture, Fisheries and Food. Household Food Consumption and Expenditure, 1988. Annual Report of the National Food Survey Committee. London: HMSO, 1989.

11 Gregory J, Foster K, Tyler H \& Wiseman N. The Dietary and Nutritional Survey of British Adults. London: HMSO, 1990.

12 Szponar L, Sekuła W, Rychlik E, Ołtarzewski M, Figurska K. Badania Indywidualnego spożycia żywności $i$ stanu odżyienia $w$ gospodarstwach domowych. [Household Food Consumption and Anthropometric Survey]. Warsaw: National Food and Nutrition Institute, 2003.

13 Polish Central Statistical Office. Warunki życia ludności w $2001 r$ [Living Conditions of the Population in 2001]. Studia i analizy statystyczne. Warsaw: Polish Central Statistical Office, Social Statistics Department, 2002. 